\section{Commentary: Ground-glass nodules: The challenge of identifying red flags amidst a background of red herrings}

\author{
Erin M. Corsini, MD, and Mara B. Antonoff, MD
}

Dr Fu and colleagues ${ }^{1}$ take on an important task: Addressing the fact that although many believe pure ground-glass nodules (pGGNs) to be relatively indolent and benign in nature, there is a subpopulation of pGGNs that include invasive adenocarcinoma. It is important to recognize this fact, and although it is unfortunate that more predictors of invasive nature were unable to be found, the identification of size as relevant is worthwhile to disseminate.

The authors have revealed that among patients with radiographically identified pGGNs that are pathologically confirmed to be primary lung adenocarcinomas, tumor size determined by axial imaging was associated with invasive adenocarcinoma, compared with adenocarcinoma in situ or minimally invasive adenocarcinoma. The discussion of management of pGGNs and associated predictors of invasive disease is pertinent because the authors note that a modest number of pGGNs are found to have invasive components at the time of pathologic examination. However, the converse to this statement is equally noteworthy: The majority of patients with pGGNs will not have invasive disease, and in fact have a benign finding (or, better yet, may actually have resolution of imaging findings). This is an important consideration as we contemplate the best strategy of integrating the findings by $\mathrm{Fu}$ and colleagues ${ }^{1}$ into routine practice. $^{2}$ Although the authors suggest that pGGN size should be used to guide prognostication and determine timing of surgical resection, we submit that a wider lens be applied in interpretation of these data.

From the Department of Thoracic and Cardiovascular Surgery, University of Texas MD Anderson Cancer Center, Houston, Tex.

Disclosures: The authors reported no conflicts of interest.

The Journal policy requires editors and reviewers to disclose conflicts of interest and to decline handling or reviewing manuscripts for which they may have a conflict of interest. The editors and reviewers of this article have no conflicts of interest.

Received for publication April 27, 2020; revisions received April 27, 2020; accepted for publication April 28, 2020; available ahead of print May 11, 2020.

Address for reprints: Mara B. Antonoff, MD, Department of Thoracic and Cardiovascular Surgery, University of Texas MD Anderson Cancer Center, 1515 Holcombe Blvd, Houston, TX 77030 (E-mail: MBAntonoff@mdanderson.org).

J Thorac Cardiovasc Surg 2021;162:460-1

$0022-5223 / \$ 36.00$

Copyright (C) 2020 by The American Association for Thoracic Surgery

https://doi.org/10.1016/j.jtcvs.2020.04.133

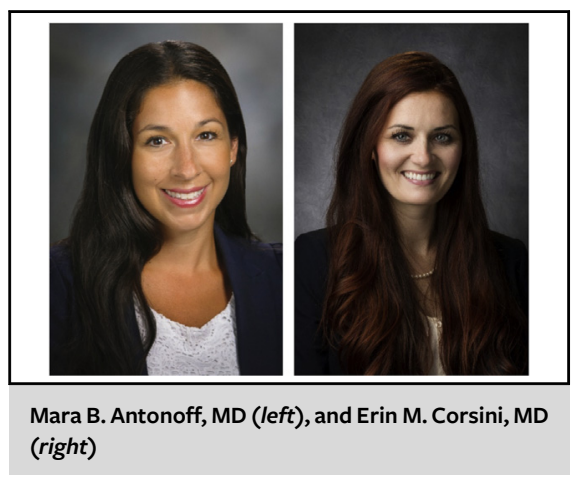

CENTRAL MESSAGE

The importance of ground-glass nodule size in identifying invasive adenocarcinoma is highlighted, although many challenges remain in determining optimal management for this population.

A number of prior reports have demonstrated the benign nature of a majority of pGGNs, highlighting the role of active, continued surveillance in a multidisciplinary care setting, particularly because such findings are increasingly reported. ${ }^{3}$ Of significant relevance in interpretation of such findings is the true denominator; $\mathrm{Fu}$ and colleagues ${ }^{1}$ have defined their cohort as having both a radiographic finding of pGGN with an ultimate designation of lung adenocarcinoma. The outcomes of those patients with pGGN who were either surveilled or underwent resection for benign disease are imperative in understanding the complex landscape of ground-glass management in its entirety. Whether pGGN size would remain associated with a pathologic finding of invasive adenocarcinoma among a more comprehensive cohort remains unknown, and it cannot be determined from the findings presented herein. Furthermore, in the absence of any solid components of the nodules in this cohort, the notion of surgical resection should again be considered cautiously because it is uncertain if the superior outcomes associated with this finding can be ascribed to aggressive surgical resection or an indolent process at the outset. $^{4,5}$

Fu and colleagues ${ }^{1}$ should be commended for their large series, important findings, and rigorous analytic methods. As thoracic surgeons, we expect interventions for aggressive disease pathology to be supported by a high preponderance of evidence and data to support associated procedural risks. For a largely benign pathology, the evidence ought to be even greater. This report by Fu and colleagues should be 
considered in the context of prior reports with equivocal findings and added to the growing body of literature highlighting the complex nature and management of pGGNs.

\section{References}

1. Fu F, Zhang Y, Wang S, Li Y, Wang Z, Hu H, et al. Computed tomography density is not associated with pathological tumor invasion for pure ground-glass nodules. J Thorac Cardiovasc Surg. 2021;162:451-9.e3.
2. Shewale JB, Nelson DB, Rice DC, Sepesi B, Hofstetter WL, Mehran RJ, et al. Natural history of ground-glass lesions among patients with previous lung cancer. Ann Thorac Surg. 2018;105:1671-7.

3. Van Haren RM, Correa AM, Sepesi B, Rice DC, Hofstetter WL, Mehran RJ, et al. Ground glass lesions on chest imaging: evaluation of reported incidence in cancer patients using natural language processing. Ann Thorac Surg. 2019;107:936-40.

4. Antonoff MB. The search for reliable markers of ground glass opacity prognosis: the truth remains largely unknown. J Thorac Cardiovasc Surg. 2018;156:814-5.

5. Antonoff MB. Multifocal lung cancer within ground glass lesions: are favorable outcomes consequent to surgical resection or inherent to the disease? J Thorac Cardiovasc Surg. 2018;155:361-2.
See Article page 451

\section{Commentary: Is size everything in the management of ground-glass opacities?}

\author{
Ka-Lun Mak, MBBS, and \\ Michael Hsin, MD, FRCS, CTh
}

The benefits of lung cancer screening have been demonstrated by the National Lung Screening and Nederlands Leuvens Screening Onderzoek trials, ${ }^{1,2}$ and clinicians will encounter increasing number of patients with groundglass opacities (GGOs). A significant proportion of persistent GGOs may turn out to be adenocarcinomas, and up to $22.7 \%$ of the resected GGOs are invasive adenocarcinomas on histology.

In this issue of the Journal, the Fu and colleagues ${ }^{4}$ from China reviewed 432 cases of resected adenocarcinoma cases that presented as pure GGO on computed tomography (CT) and reported that CT density could not separate invasive from preinvasive histology. The size of the GGO, specifically at $1.05-\mathrm{cm}$ cutoff, was the only factor that correlated with invasive adenocarcinoma, which resonates with the TNM $8^{\text {th }}$ edition in which size increments at $1 \mathrm{~cm}$ translate into survival differences for T1 tumors. ${ }^{5}$

\footnotetext{
From the Department of Cardiothoracic Surgery, Queen Mary Hospital, Hong Kong, China.

Disclosures: The authors reported no conflicts of interest.

The Journal policy requires editors and reviewers to disclose conflicts of interest and to decline handling or reviewing manuscripts for which they may have a conflict of interest. The editors and reviewers of this article have no conflicts of interest.

Received for publication April 30, 2020; revisions received April 30, 2021; accepted for publication May 12, 2021; available ahead of print May 19, 2021.

Address for reprints: Michael Hsin, MD, FRCS, CTh, Department of Cardiothoracic Surgery, Queen Mary Hospital, Room 308, New Clinical Building, Hong Kong, China (E-mail: mkhsin@hotmail.com).

J Thorac Cardiovasc Surg 2021;162:461-2

$0022-5223 / \$ 36.00$

Copyright (c) 2021 by The American Association for Thoracic Surgery

https://doi.org/10.1016/j.jtcvs.2021.05.023
}

Check for updates

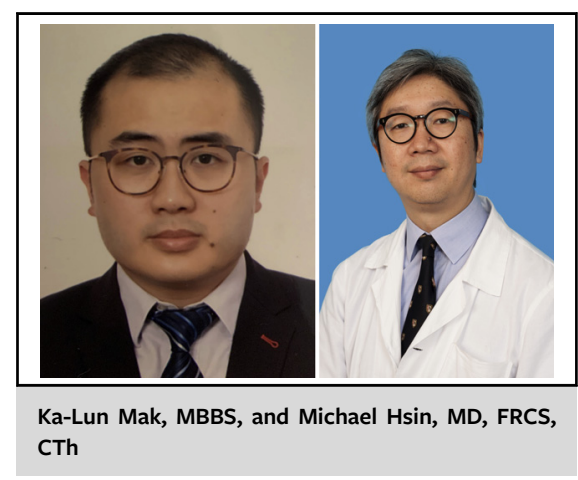

CENTRAL MESSAGE

The size of GGOs can separate preinvasive from invasive adenocarcinoma. Changes over time of GGOs and individual patient factors are important factors in the decision for and timing of resection.

The Fudan article adds to the literature in that (1) this is the largest series of pure GGO adenocarcinomas; (2) they excluded atypical adenomatous hyperplasia (AAH) cases and grouped adenocarcinoma in situ with minimally invasive adenocarcinoma together as the preinvasive group to compare with the invasive adenocarcinomas; and (3) they focused on CT density as one of the parameters to differentiate preinvasive from invasive groups.

The findings of the Fudan group differed from previous publications regarding CT density, likely because they excluded AAH in the preinvasive category. Kitami and colleagues ${ }^{6}$ found that for the association with $\mathrm{AAH}$, a combination of GGO size and CT density can achieve $90 \%$ 